\title{
SOSIALISASI PENGISIAN SISTER BAGI DOSEN PESERTA SERTIFIKASI TAHUN 2020
}

\author{
${ }^{1)}$ Roki Hardianto, ${ }^{2)}$ Wirdahchoiriah, ${ }^{3)}$ Fana Wiza \\ ${ }^{1)}$ Teknik Informatika, Fakultas Ilmu Komputer, Universitas Lancang Kuning \\ ${ }^{2,3)}$ Sistem Informasi, Fakultas Ilmu Komputer, Universitas Lancang Kuning \\ ${ }^{1,2,3)}$ Jl. Yos Sudarso KM. 08, Rumbai, Pekanbaru - Riau - Indonesia \\ E-mail : roki@unilak.ac.id,wirdah@unilak.ac.id,fanawiza@unilak.ac.id
}

\begin{abstract}
ABSTRAK
Kegiatan ini adalah memberikan pendampingan kepada kelompok dosen-dosen Universitas Lancang Kuning, khususnya kepada dosen peserta sertifikasi dosen tahap I tahun 2020. Team pengabdian akan memaparkan teknik serta cara pengimputan diawali dengan menjelaskan fungsi dari aplikasi Sister (www.sister.unilak.ac.id) bagi dosen baik peserta sertifikasi dosen maupun dosen yang telah tersertifikasi. Peserta sertifikasi wajib menginputkan data diri, riwayat pendidikan, riwayat jabatan fungsional, riwayat pelaksanaan pendidikan, riwayat penelitian, riwayat pengabdian dan data pendukung lainnya. Semua peserta dijelaskan aturan dalam proses penginputan data terutama ukuran maksimal data yang bisa diinputkan hingga trik cepat agar dapat menginputkan data diri pada aplikasi tersebut. Dari 10 fakultas yang ada di Universitas Lancang Kuning, 72 dosen dapat melanjutkan pada tahapan D3 hingga tahapan D4. Sedangkan pada tahapan D5 hanya 51 dosen yang dapat melanjutkan karena seleksi proses penilaian dari system. Team pengabdian membuat WAG dalam memandu proses input data system dalam rangka proses sertifikasi. Hal inii dilakukan agar dapat memantau dan membantu jika ada kendala dalam proses sertifikasi.
\end{abstract}

Kata kunci: serdos, sister, fasilkom, unilak, dosen

\section{ABSTRACT}

This activity is to provide assistance to the group of Lancang Kuning University lecturers, especially to the lecturers participating in the Phase I lecturer certification in 2020. The service team will explain the techniques and methods of collection starting with explaining the functions of the Sister application (www.sister.unilak.ac.id ) for lecturers both lecturer certification participants and certified lecturers. Certification participants must enter their personal data, educational history, functional position history, education implementation history, research history, service history and other supporting data. All participants explained the rules in the process of inputting data, especially the maximum size of data that can be input up to a quick trick in order to be able to input data themselves on the application. Of the 10 faculties at Lancang Kuning University, 72 lecturers can continue at stage D3 to stage D4. Whereas at stage D5 only 51 lecturers were able to proceed because of the selection process for the assessment of the system. The dedication team made WAG in guiding the data system input process in the framework of the certification process. This is done so that they can monitor and assist if there are obstacles in the certification process.

Key words : serdos, sister, fasilkom, unilak, lecturers

\section{PENDAHULUAN}

Sister (Sistem Informasi Sumbar Daya Terintegrasi) adalah aplikasi dari Kementerian Pendidikan dan Kebudayaan yang bertujuan mendata dosen se Indonesia. Didalam sister terdapat riwayat kegiatan dosen secara lengkap yang dapat digunakan sebagai salah satu syarat untuk mengikuti sertifikasi dosen (serdos). Dengan tujuan agar semua kegiatan dosen dapat dipantau oleh universitas dan kementerian yang menaungi. 


\section{$\underline{E_{3}}$ \\ Sister Ristekdikti \\ Sistem Informasi Sumberdaya Terintegrasi}

Dengan dilaksanakannya sertifikasi, dosen diakui professional dalam bidangnya yang diakui oleh pemerintah. Pada tahun 2020 pelaksanaan sertifikasi dosen dilaksanakan dengan menggunakan aplikasi sister yang dikeluarkan oleh pemerintah. Dosen diwajibkan menginputkan data diri, kepangkatan, riwayat pendidikan, pelaksanaan pendidikan, riwayat penelitian, pengabdian serta riwayat pelaksanaan kegiatan yang berhubungan dengan tridharma perguruan tinggi.

\section{METODE PELAKSANAAN}

Pengabdian Masyarakat akan dilaksanakan di Universitas Lancang Kuning. Pelaksanaanya menggunakan metode praktek langsung, tanya jawab, dan evaluasi data yang diinputkan. Pelatihan dilakukan selama beberapa hari dimana peserta akan mendapatkan buku panduan pengimputan sister.

Rincian kegiatan adalah sebagai berikut :

1. Perkenalan team Pengabdian Masyarakat

2. Memastikan akun sister dosen sudah bisa login

3. Pendalaman materi pelatihan

4. Melakukan praktek

5. Melakukan tanya jawab

Kegiatan ini menggunakan bebarapa perangkat pendukung di antaranya adalah :

1. Perangkat komputer / laptop

2. Infocus

3. Aplikasi Sister Universitas Lancang Kuning (www.sister.unilak.ac.id)

4. Serta peralatan pendukung lainnya

\section{HASIL}

Kegiatan Pengabdian Kepada Masyarakat ini dilaksanakan di fakultas-fakultas di Universitas Lancang Kuning. Pada kegiatan ini semua dosen dipandu dalam agar mampu mengisi data diri dosen didalam aplikasi SISTER (Sistem Informasi Sumber Daya Terintegrasi) Sistem merupakan 
aplikasi keluaran dari Kementerian Pendidikan Kebudayaan dan Pendidikan Tinggi Republik Indonesia. Aplikasi ini berfungsi mencatat semua identitas dosen berupa data diri, riwayat pendidikan, riwayat jabatan fungsional, riwayat pendidikan, riwayat pelaksanaan pendidikan, riwayat penelitian, riwayat pengabdian kepada masyarakat serta data pendukung lainnya.

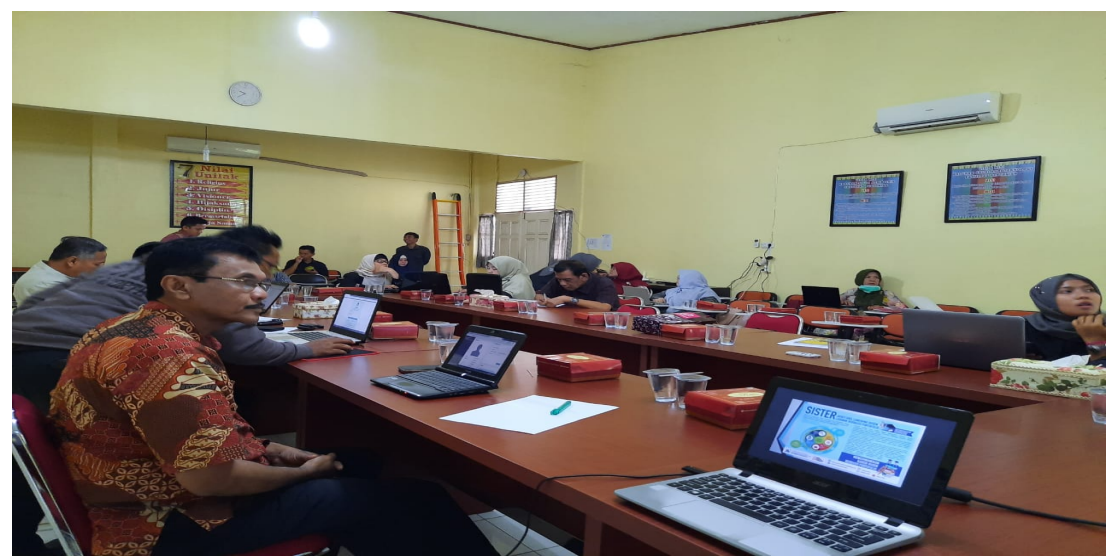

Gambar 1. Pelatihan Sister Di Fakultas Pertanian

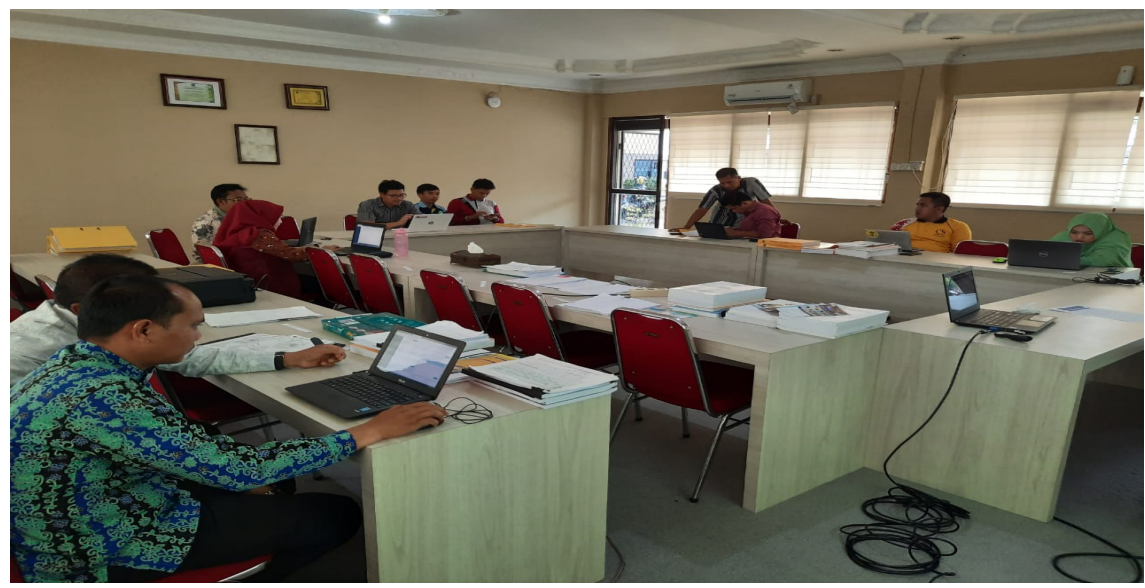

Gambar 2. Pelatihan Sister Di Fakultas Administrasi

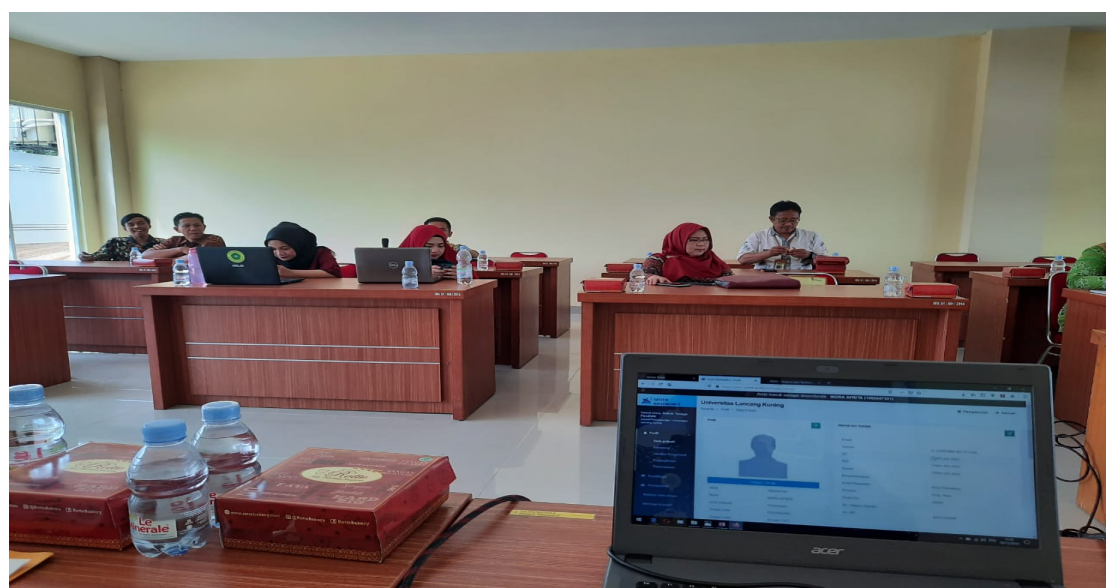

Gambar 3. Pelatihan Sister Di Pasca Sarjana

Kegiatan tersebut dilaksanakan denga metode seminar. Pada tahapan pertama dosen diarahkan untuk mendaftar akun sister. Kemudian para dosen diarahkan untuk melengkapi data diri yang 
bersumber dari data KTP dan Kartu Keluarga, ijazah dan trakrips S1, S2 dan S3, SK jabatan fungsional dosen. Dosen sering kesulitan dalam menginputkan data diri karena beberapa jenis data yang diinputkan mengharuskan melampirkan data yang valid dengan ukuran data tertentu. Jika ukuran lampiran tidak sesuai dengan ketentuan dari sister, maka system automatis menolak dan gagal dalam menyimpan data.

Beberapa tahapan dalam dosen dalam menginut Sister :

1. Dosen menginputkan data pada Sister

Pada tahapan ini dosen menginputkan data diri dengan melampirkan lampiran dari KK, KTP, surat keterangan jabatan fungsional, inpassing, ijazah dan transkrip nilai. Setelah dosen berhasil menginputkan data diri maka dosen wajib melakukan ajuan data yang akan divalidasi oleh admin perguruan tinggi dan admin LLDIKTI

2. Validasi data ajuan oleh admin perguruan tinggi

Pada tahapan ini admin perguruan tinggi akan memvaliadasi data ajuan dosen. Pada tahapan ini admin dapat memvalidasi data dosen dengan status ajuan disetujui, ditolak dan ditangguhkan. Pada status disetujui admin akan memperhatikan antara data ajuan dan lampiran data. Ditolak jika antara data ajuan berbeda dengan lampiran. Ditangguhkan jika data ajuan ada perbedaan beberapa item yang bisa diperbaharui dengan lampiran data. Saat admin perguruan tinggi memvalidasi dengan status disetujui maka ajuan dosen masuk ketahapan validasi data ajuan admin LLDIKTI. Sedangkan pada status ditolak dan ditangguhkan maka ajuan akan dikembalikan keakun dosen untuk diperbaiki.

3. Validasi data ajuan oleh admin LLDIKTI

Data dosen yang masuk dalam tahapan validasi data ajuan oleh admin LLDIKTI adalah data validasi disetujui oleh akun admin perguruan tinggi. Pada data ajuan yang masuk dalam tahapan ini, admin juga dapat merubah status ajuan berdasarkan ajuan dan lampiran data valid untuk disetujui, ditolak dan ditangguhkan.

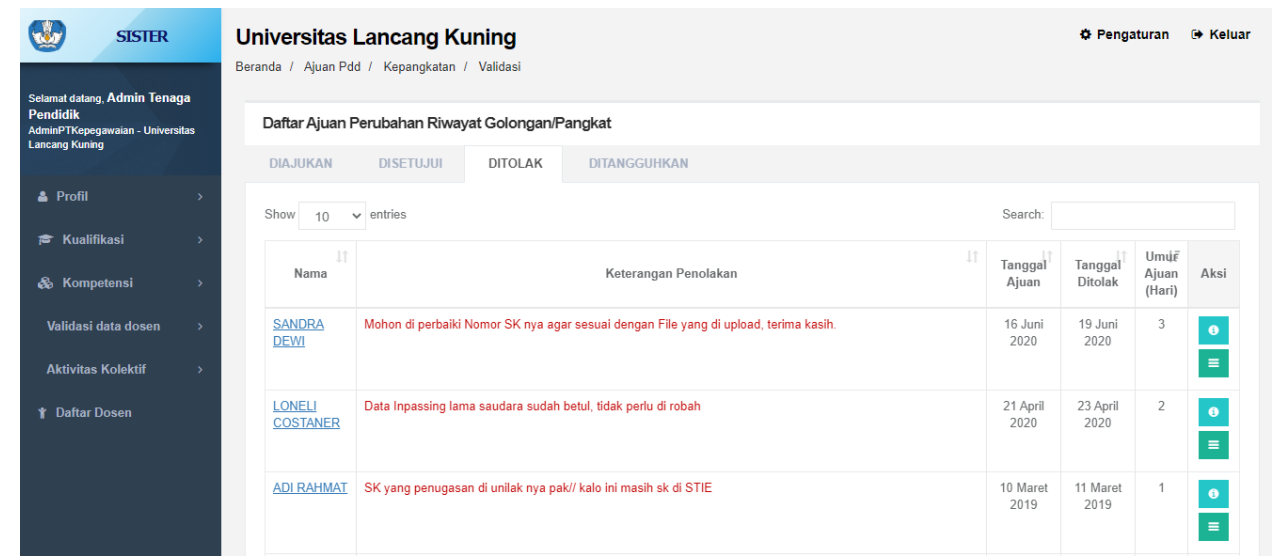

Gambar 4. Status Ajuan Dosen

Luaran yang dicapai dari kegiatan sosialisasi sister kepada dosen Universitas Lancang Kuning yang terdiri dari beberapa fakultas adalah sebanyak 72 peserta dosen yang elegible mengikuti data D1 pada proses serdos tahap 1 tahun 2020. Kemudian setelah proses seleksi berkas 
yang dilakukan melalui sister maka yang masuk dalam data D3 adalah 66 peserta dosen diajuakan oleh pimpinan perguruan tinggi. Secara otomatis 66 peserta dosen tersebut lolos pada tahapan D4.

Pada tahapan serdos dose nada beberapa tahapan yang harus dilalui, diantaranya :

1. D1 adalah tahapan seleksi dosen dari sister berdasarkan data inputan

2. D2 adalah dosen yang masih kurang inputan data inpassing

3. D3 adalah hasil pengecekan kelengkapan data dosen oleh admin perguruan tinggi

4. D4 adalah klaim data isian sister untuk diajukan dalam pada proses serdos. Ketika data diklaim, sister akan menyeleksi kelengkapan data terutama lampiran data. Ketika data yang diklaim tidak lengkap maka sister akan mengingatkan dosen kekurangan data lampiran. D4 yang diklaim berhubungan dengan D5 yaitu deskripsi diri.

5. D5 adalah dosen yang lolos D4 untuk mengisi deskripsi diri berdasarkan data klaim D4 dengan menjawab pertanyaan yang disediakan sister.

6. Proses kelulusan adalah hasil cek deskripsi diri dan data diri dosen oleh reviewer.

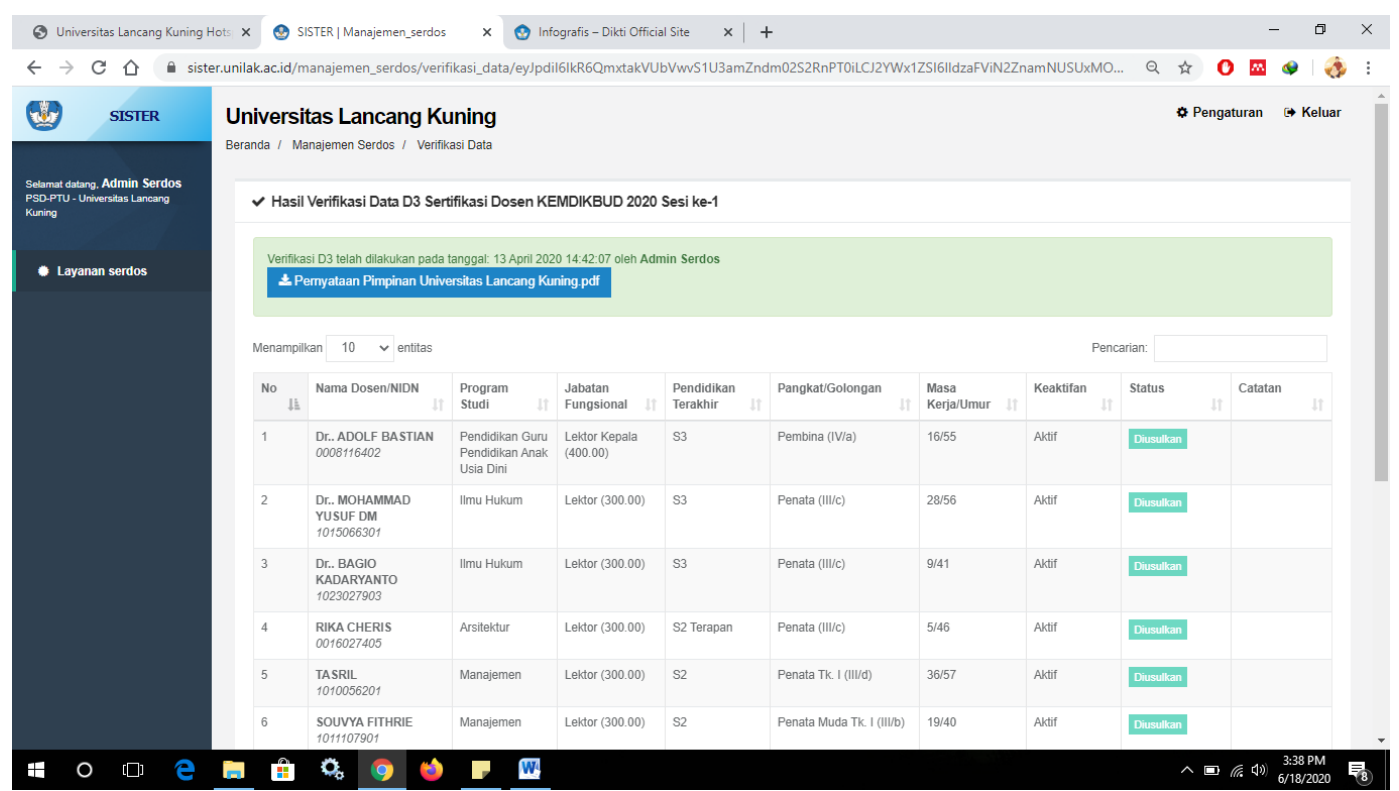

Gambar 5. Data Dosen Lolos D3

Pada proses serdos periode 1 tahun dosen yang lolos pada proses D3 akan melanjutkan pada proses D4. D4 adalah dosen melakukan klaim kegiatan tridarma perguruan tinggin dan mengisi kuisioner yang disediakan oleh sister kepada pimpinan, teman sejawat dan mahasiswa. Nilai dari kuisioner dan nilai tes TKDA dan TOEP akan diakumulasikan berdasarkan tabel perhitungan yang telah ditetapkan oleh dirjen pendidikan tinggi. Pada proses D4, 15 dosen gagal untuk melanjutkan ketahapan D5 karena kurang jumlah nilai akumulasi penilaian kuisioner dan tes TKDA dan TOEP. 51 peserta dosen lolos untuk mengikuti tahapan D5 yaitu pengisian deskripsi diri.

Berikut ini adalah tabel akumulasi jumlah dosen yang lolos dari tahapan D1, D2, D3, D4. 


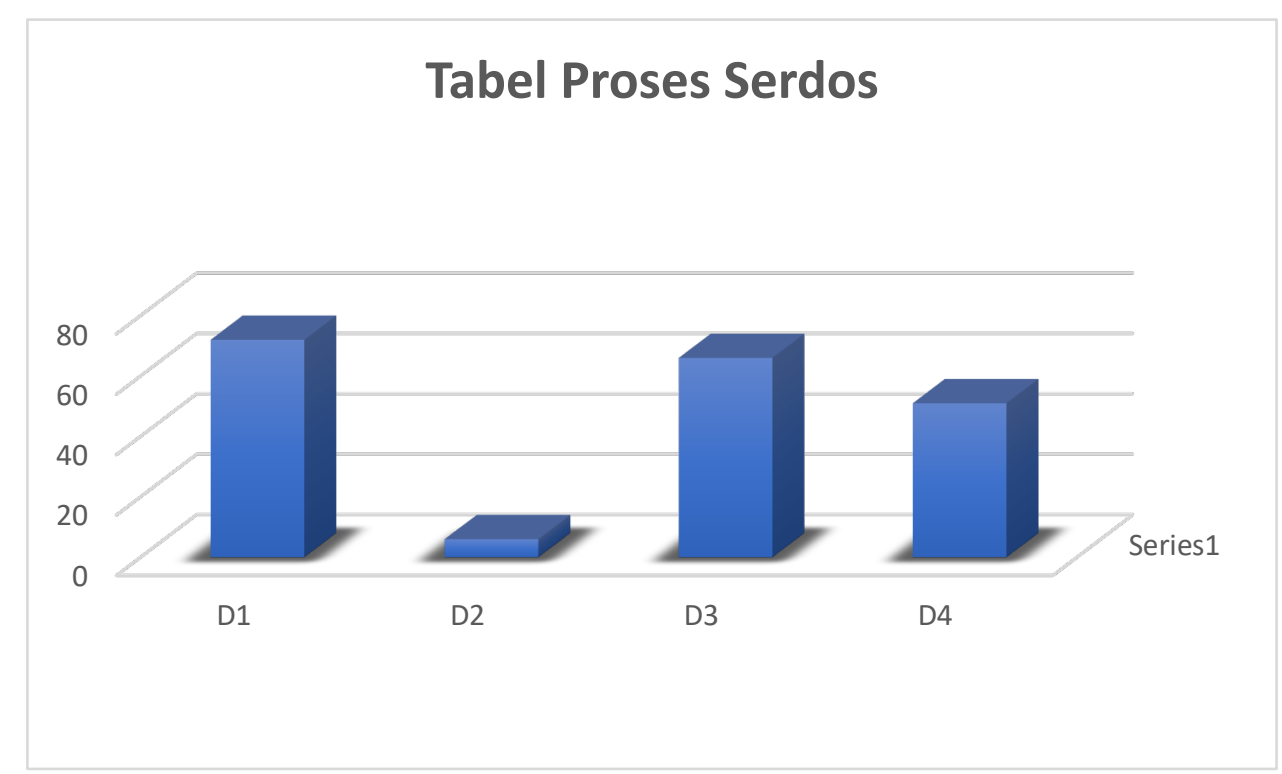

Tabel 6. Tabel Proses Serdos

\section{KESIMPULAN}

Dari kegiatan pengabdian kepada masyarakat diatas dapat ditarik kesimpulan, pada proses serdos tahap 1 tahun 2020 pelaksanaannya dari akun sister. Dosen diwajibkan melengkapi data sister masing-masing dosen agar bisa lolos dan dapat melanjutkan ketahapan berikutnya. Ketelitian dan konsistensi dosen dalam melengkapi data pada sister menentukan dosen lolos dari tahap D1 hingga tahapan D5. 72 peserta dosen lolos tahap D1 sedangkan yang lolos untuk dapat melanjutkan hingga tahapan D5 adalah 51 peserta dosen..

\section{DAFTAR PUSTAKA}

[1] Jogiyanto. (2017). Konsep Dasar Sistem Informasi. Konsep Dasar Sistem Informasi.

[2] Kadir, A. (2014). Konsep Spasial Peningkatan Profesionalitas Guru Dan Dosen. Shautut Tarbiyah, 2014: Ed. Ke-30 Th. Xx, Mei 2014.

[3] Nuraeni, Y. (2009). Pembangunan Sistem Informasi Untuk Penyelenggaraan Sertifikasi Dosen Di Indonesia. Jurnal Ilmu Komputer Dan Informasi. Https://Doi.Org/10.21609/Jiki.V2i2.133

[4] Sonia Piscayanti, K. (2015). Pengaruh Sertifikasi Dosen Terhadap Kinerja Pengajaran Dosen Undiksha. Jurnal Ilmu Sosial Dan Humaniora. Https://Doi.Org/10.23887/JishUndiksha.V4i1.4922 